\title{
Effect of Some Alternative Components of Egg Yolk in Tris-Extender on Sperm Characteristics of Ram Semen Frozen with Two Methods of Packaging Semen \\ Abdel-Khalek, A. E. ${ }^{\text {; } ~ W . ~ A . ~ K h a l i l ~}{ }^{1}$; B. E. El-Saidy ${ }^{2}$ and A. I. A. Yousif ${ }^{2}$ \\ ${ }^{1}$ Department of Animal Production, Faculty of Agriculture, Mansoura University, Mansoura 35516, Egypt \\ ${ }^{2}$ Animal Production Research Institute, Agriculture Research Center, Dokki, Giza, Egypt
}

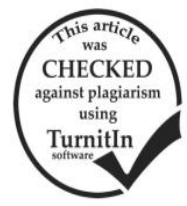

\section{ABSTRACT}

This study aimed to evaluate the effect of alternative components of egg yolk in Tris extender and semen packaging methods during cryopreservation on sperm characteristics and antioxidant system in seminal plasma of frozen-thawed semen of Finnish Landrace rams. Semen was collected from 5 sexually matured Finnish rams (50-70 kg LBW and 2-4 years old) by artificial vagina once weekly for 7 weeks. Only semen with mass motility of $\geq 70 \%$ was pooled and diluted with Tris-citric extender containing 15\% egg yolk (Tris-EY) or 1\% soybean lecithin (Tris-SBL) or $2 \mathrm{mM}$ butylated hydroxytoluene (Tris-BHT). Semen was extended at a rate of 1:5 (semen/extender) with three extender types. After semen extension, semen was placed for cooling in the refrigerator $\left(5^{\circ} \mathrm{C}\right)$ for 4 hours as equilibration period and packaged in $0.25 \mathrm{ml}$ French straws or $0.25 \mathrm{ml}$ pellets in liquid nitrogen. Semen was thawed at $37^{\circ} \mathrm{C}$ for $30 \mathrm{~s}$. Semen was evaluated after dilution, equilibration and thawing, for progressive motility, livability and abnormality of spermatozoa and curled tail spermatozoa responded to a solution of osmolarity of $75 \mathrm{mOsm}$ for $30 \mathrm{~min}$. The concentration of total antioxidants (TAC), malondialdehyde (MDA) and lactic dehydrogenase (LDH) activity in post-thawed seminal plasma were determined. Results showed that sperm characteristics, including percentages of progressive motility, livability, abnormality and curled tail in post-diluted, post-equilibrated or post-thawed semen were not affected significantly by the type of extender. Progressive motility and curled tail percentages in post-thawed semen were higher $(\mathrm{P}<0.001 ; \mathrm{P}<0.05)$ in straws than in pellets. Livability and abnormality percentages were insignificantly better at straws than in pellets. The recovery rate of motility and livability was higher at straws than in pellets. All sperm characteristics indicated insignificant effect of interaction between type of extender and semen packaging method. TAC was higher $(\mathrm{P}<0.05)$, while MDA concentration was lower $(\mathrm{P}<0.05)$ in Tris-SBL and Tris-BHT than in Tris-EY. The activity of LDH was insignificantly the highest in Tris-BHT than in other extenders. The TAC, MDA concentration and LDH activity in post-thawed semen were not affected significantly by semen packaging method. Effects of interaction between type of extender and semen packaging method on each of TAC, MDA concentration and LDH activity were not significant. The current study concluded the successful usage of Tris-SBL or Tris-BHT in comparing with the possible disadvantages of using egg yolk in Tris-based extender of ram semen.

Keywords: Ram semen, lecithin, butylated hydroxytoluene, sperm function, antioxidant capacity.

\section{INTRODUCTION}

Chilled-frozen semen is the most potent technique for rapid genetic improvement in domestic animals using artificial insemination (AI) (Ax et al., 2000). In mammalian spermatozoa, high concentrations of polyunsaturated fatty acids (PUSFA) in the plasma membrane and lack of antioxidant enzymes in spermatozoa (Ziaullah et al., 2012) leads PUSFA to volatile to reactive oxygen species (ROS), induced a subsequent sperm functions loss and peroxidative damage in mammalian spermatozoa (Nair et al., 2006). Therefore, mammalian sperm preservation is a complex process, including several factors in order to obtain good semen quality (Ferdinand et al., 2014). Cryoprotectants, extenders, cooling rates, thawing rates and semen packaging method are major factors affecting cryopreservation success (Cotter et al., 2005; Andrabi, 2007; Clulow et al., 2008). Successful storage and quality of semen may vary depending on the extender used (Salamon and Maxwell, 2000). Extender composition aids with the stabilization of cells during the freezing-thawing process (Nur et al., 2010).

Egg yolk is considered to be an excellent cryoprotectant for the sperm cryopreservation at various concentrations in different species (Demianowicz and Strezek, 1996). The accurate mechanism of egg yolk which aids to protect sperm during freezing process is unknown. However, (Moussa et al., 2002) has suggested that the low-density lipoproteins (LDL) of egg yolk could protect spermatozoa against cold shock and improve sperm motility. Also, LDL could protect sperm membranes by involving to cell membranes during the freezing-thawing process (Graham and Foot, 1987). Furthermore, the presence of substances in the yolk that prevents the gaseous exchange of sperm or decreases sperm motility has accelerated the demand to replace whole egg yolk with the cryoprotective fraction alone (Pace and Graham, 1974; Watson and Martin, 1975; Haidl and Schill, 1994).

Egg yolk and skim milk are the most widely used as a non-penetrating cryoprotectants for preserving goat spermatozoa (Purdy, 2006) and ram, bull, equine, boar and human semen because it can protect the membrane damage as a result of its large content of lecithin (Rehman et al., 2014). Egg yolk, seminal plasma and milk proteins as animal principle ingredients increase the risk of microbial contamination of semen storage media (Wrathall et al., 2008). Soybean lecithin (SBL) extender as a lipid/lipoprotein source can be a substitute component of the animal's origin ingredients (Vidal et al., 2013) as skimmed milk (Papa et al., 2011) or conventional extenders that include egg yolk (Zhang et al., 2009) in semen extenders for semen cryopreservation. Also, butylated hydroxytoluene (BHT) has been tested as a cryoprotectant potentiality and optimal inclusion level in canine semen (Sahashi et al., 2011). The BHT has been used for minimizing 
cryoinjury in cryopreserving semen of rams (Watson and Anderson, 1983), bovine bulls (Shoae and Zamiri, 2008), goats (Naijian et al., 2013) and human (Merino et al., 2015).

On the other hand, freezing method semen choice depends on individual preferences and needs. Variable effects have been occurred by semen packaging (straw or pellets) on sperm motility after the freezing-thawing process in ram (Awad, 1989) and rabbits (Daader and Zeidan, 2008).

Therefore, this study aimed to evaluate the effect of alternative components of egg yolk (SBL or BHT) in Trisextender and semen packaging methods (straws or pellets) during cryopreservation on sperm characteristics and antioxidant system in seminal plasma of frozen-thawed Finnish rams semen.

\section{MATERIALS AND METHODS}

The current study was carried out at Animal Production Research Station, Sakha, Kafrelsheikh Governorate, located in the northern part of Nile Delta (latitude $31^{\circ} 15^{\prime} \mathrm{N}$ and longitude $31^{\circ} 45^{\prime} \mathrm{E}$ ), belonging to Animal Production Research Institute (APRI), Agricultural Research Center, Ministry of Agriculture, Egypt, in cooperation with Physiology and Biotechnology Laboratory, Department of Animal Production, Faculty of Agriculture, Mansoura University, Egypt, during the period from August, 2016 until February, 2017.

Animals:

A total of 5 sexually matured Finnish Landrace rams (50-70 kg LBW) aged (2-4 years), adaptability to semen collection by artificial vagina were selected for semen collection. All experimental animals were raised under the same environmental conditions in the experimental farm and kept under the semi-open shaded yard.

Feeding requirements were calculated according to the recommendations of APRI, Ministry of Agriculture, Egypt. Each ram was fed concentrate feed mixture (CFM) at a level of $1.250 \mathrm{~kg}(14 \% \mathrm{CP})$ plus $1.250 \mathrm{~kg}$ berseem hay during August-November or $5 \mathrm{~kg}$ Egyptian fresh berseem (Trifolium alexandrinum) during December-February, with free access to trace mineralized salt lick blocks and drinking water all time.

Semen collection:

Semen was collected from 5 Finnish rams once weekly for 7 weeks before feeding at 7.0 a.m. to 8.0 a.m. by using the conventional artificial vaginal method (35 ejaculates). Semen ejaculates were transferred immediately after collection to the laboratory and then placed in water bath at $37^{\circ} \mathrm{C}$. Only semen with mass motility of $\geq 70 \%$ was pooled and divided into three extender types and two methods of semen packaging (straws and pellets).

Semen extender preparation:

Tris-citric-egg yolk extender (Tris-EY) containing $3.025 \mathrm{~g}$ Tris (Sigma Chemical Co., St. Louis, MO, USA), $1.66 \mathrm{~g}$ citric acid monohydrate (Sigma), 1.25 g glucose (Sigma, Aldrich), 15\% fresh egg yolk,
5\% glycerol, $100 \mathrm{IU} / \mathrm{ml}$ penicillin and $100 \mu \mathrm{g} / \mathrm{ml}$ streptomycin was used as a control extender. Egg yolk $(15 \%)$ in Tris-EY was replaced by $1 \%$ soybean lecithin (L-a-phosphatidyl choline, LAB: product number MC041) in the $2^{\text {nd }}$ extender (Tris-SBL) or $2 \mathrm{mM}$ butylated hydroxytoluene (BHT) in the $3^{\text {rd }}$ extender (Tris-BHT).

Extenders were gently shaken and warmed up to $37^{\circ} \mathrm{C}$ in a water bath before use. Osmolarity and $\mathrm{pH}$ were assessed before addition of cryoprotectants and was adjusted to the osmolarity of $300 \mathrm{mOsmol}$ and $\mathrm{pH}$ value of 7.3 .

\section{Semen freezing and thawing}

Immediately, tubes containing the extended semen was gently shaken and placed in a water bath containing warm water $\left(37^{\circ} \mathrm{C}\right)$. Pooled semen was diluted at a ratio of 1:5 (semen/extender) with three extender types. After semen extension, semen was placed for cooling in the refrigerator $\left(5^{\circ} \mathrm{C}\right)$ for 4 hours as equilibration period.

Equilibrated semen was frozen by two methods of packaging, the first was $0.25 \mathrm{ml}$ French straws (IMV, L'Agile France) and the $2^{\text {nd }}$ was $0.25 \mathrm{ml}$ pellets. The straws were then plunged into liquid nitrogen at $-196^{\circ} \mathrm{C}$, while pellets were made according to Awad (1989).

At least three straws and three pellets from each extender type of pooled ejaculates $(n=7)$ were thawed in a water bath at $37^{\circ} \mathrm{C}$ for $30 \mathrm{~s}$ to evaluate sperm characteristics in post-thawed semen.

\section{Semen evaluation:}

Progressive motility, livability and abnormality of spermatozoa were assessed, and curled tail spermatozoa responded to a solution of osmolarity of 75 mOsml in term hypo-osmotic swelling test (HOS-t) for $30 \mathrm{~min}$ was also assessed by adding $0.1 \mathrm{ml}$ of semen sample in a tube contains $0.9 \mathrm{ml}$ of HOS media. These parameters were evaluated immediately in post-diluted, post-equilibrated and post-thawed semen.

\section{Antioxidants analysis:}

Concentration of total antioxidants (Koracevic et al. 2001), malondialdehyde (MDA, Ohkawa et al., 1979) and lactic dehydrogenase (LDH) activity (Bais and Philcox, 1994) were determined in post-thawed seminal plasma using commercial kits (Biodiagnostic, Egypt) and spectrophotometer (SPECTRO UV-VIS AUTO, UV-2602, Labomed, USA).

\section{Statistical analysis:}

The General Linear Model procedures of (SAS 2004), GLM analysis of variance (ANOVA, two ways design) were used for statistically analyzing data to determine the effect of extender type, semen packaging method and their interaction on sperm characteristics and antioxidant system in semen of Finnish rams. The Differences among treatment means were tested according to Duncan multiple range tests (Duncan 1955).

\section{RESULTS}

\section{Sperm characteristics:}

\section{Effect of type of extender:}

Sperm characteristics, including percentages of progressive motility, livability, abnormality and curled tail (membrane integrity in response to HOS-t) either in post-diluted, post-equilibrated or post-thawed Finnish ram semen were not affected significantly by the type of extender (Table 1). 
Table 1. Sperm characteristics in post-diluted, post-equilibrated and post-thawed semen of Finnish rams as affected by the extender type.

\begin{tabular}{lcccc}
\hline & \multicolumn{4}{c}{ Sperm characteristics (\%) } \\
\cline { 2 - 5 } Type of Extender & Progressive sperm motility & Sperm livability & Sperm abnormality & Curled tail spermatozoa \\
\hline Post-diluted semen: & & & & \\
Tris-EY & $77.10 \pm 1.81$ & $69.80 \pm 1.68$ & $12.00 \pm 0.65$ & $68.80 \pm 3.38$ \\
Tris-SBL & $75.70 \pm 2.00$ & $67.40 \pm 0.97$ & $12.80 \pm 1.67$ & $67.10 \pm 3.97$ \\
Tris-BHT & $75.00 \pm 2.15$ & $65.40 \pm 0.90$ & $13.40 \pm 1.13$ & $65.40 \pm 4.03$ \\
P-value & 0.75 & 0.06 & 0.24 & 0.26 \\
Post-equilibrated semen: & & & & $62.14 \pm 0.9$ \\
Tris-EY & $69.28 \pm 2.0$ & $64.28 \pm 1.0$ & $14.00 \pm 1.2$ & $62.85 \pm 1.1$ \\
Tris-SBL & $68.57 \pm 2.1$ & $62.85 \pm 0.9$ & $15.57 \pm 1.4$ & $0.14 \pm 1.5$ \\
Tris-BHT & $67.85 \pm 1.5$ & $62.00 \pm 0.6$ & $15.28 \pm 1.4$ & 0.59 \\
P-value & 0.86 & 0.19 & 0.67 & $46.64 \pm 1.75$ \\
Post-thawed semen: & & & & $46.78 \pm 1.38$ \\
Tris-EY & $45.35 \pm 1.33$ & $46.28 \pm 1.40$ & $34.4 \pm 1.10$ & $46.57 \pm 1.34$ \\
Tris-SBL & $45.00 \pm 1.28$ & $45.64 \pm 1.46$ & $35.5 \pm 1.10$ & 0.99 \\
Tris-BHT & $43.57 \pm 1.10$ & $44.92 \pm 1.34$ & $36.4 \pm 1.12$ & 0.46 \\
P-value & 0.57 & 0.70 & & \\
\hline
\end{tabular}

Despite the observed insignificant differences among different types of extenders used in this study on sperm characteristics during different semen processes. Tris-EY showed a lower rate of decrease in motility, livability and curled tail of spermatozoa and lower increase in sperm abnormality after dilution as compared to Tris-SBL and Tris-BHT. However, both Tris-SBL and Tris-BHT showed an opposite trend of

Table 2. Change rate $(\%)$ in sperm characteristics after dilution, equilibration and thawing of Finnish ram as affected by the extender type.

\begin{tabular}{lcccc}
\hline & \multicolumn{4}{c}{ Sperm characteristics (\%) } \\
\cline { 2 - 5 } Extender Type & Motility & Livability & Abnormality & Curled tail \\
\hline Fresh semen & 78.5 & 75.4 & 8.8 & 74.0 \\
\hline After dilution: & & & & -7.02 \\
Tris-EY & -1.78 & -7.42 & 36.36 & -9.32 \\
Tris-SBL & -3.50 & -10.61 & 45.45 & -11.62 \\
Tris-BHT & -4.45 & -13.26 & 52.27 & -9.68 \\
After equilibration: & & & & -6.33 \\
Tris-EY & -10.14 & -7.90 & 16.66 & -6.51 \\
Tris-SBL & -9.41 & -6.75 & 21.56 & -24.94 \\
Tris-BHT & -9.53 & -5.19 & 14.72 & -25.56 \\
After freezing/thawing: & & & & -23.83 \\
Tris-EY & -34.54 & -28.00 & 145.71 & 180.00 \\
Tris-SBL & -34.37 & -27.38 & 138.21 & \\
Tris-BHT & -35.78 & -27.54 & & \\
\hline
\end{tabular}

\section{Effect of semen packaging method:}

Sperm characteristics, including percentages of progressive motility and curled tail in post-thawed Finnish ram semen, were higher significantly $(\mathrm{P}<0.001$; $\mathrm{P}<0.05)$ in semen of straws than that in pellets form. Also, sperm characteristics, including percentages of livability and abnormality tended to be better in semen of straw than in pelleted semen, but the differences were not significant (Table 3 ).

Table 3. Sperm characteristics in post-thawed semen of Finnish rams as affected by semen packaging method.

\begin{tabular}{lcccc}
\hline \multirow{2}{*}{ Item } & \multicolumn{2}{c}{ Sperm characteristics (\%) } \\
\cline { 2 - 5 } & Motility & Livability & Abnormality & Curled tail \\
\hline Semen packaging method: & & & $35.8 \pm 1.01$ & $48.57 \pm 0.89^{\mathrm{a}}$ \\
Straw & $45.47 \pm 1.08^{\mathrm{a}}$ & $48.71 \pm 1.09$ & $35.1 \pm 0.79$ & 0.640 \\
Pellet & $43.80 \pm 0.91^{\mathrm{b}}$ & $42.52 \pm 0.66$ & - & $0.030^{*}$ \\
P-value & 0.260 & $0.0001 * * *$ & - \\
PE semen ${ }^{(1)}$ & 68.56 & 63.04 & - & - \\
Recovery rate: & & & - \\
Straw & 66.32 & 77.26 & - \\
Pellet & 63.88 & 67.44 & -
\end{tabular}

Tris-EY after equilibration. Yet, all types of extenders exhibited similar trend of change in all sperm characteristics in frozen/thawed semen (Table 2)

These effects reflected nearly similarity in using soybean lecithin (SBL) or butylated hydroxytoluene (BHT) as an alternative to egg yolk in the Tris-based extender, regardless semen packaging method.
When the effect of semen packaging methods was expressed in term of recovery rate, also packaging semen in straws showed a higher recovery rate of sperm motility and livability than those packaged in pellets form (Table 3).

Such result showed that freezing ram semen in straws is better than in pelleted form, regardless type of extender.

\section{* Significant differences at $\mathbf{P}<0.05$. *** Significant differences at $\mathbf{P}<0.001$. PE: Post-equilibrated}


Effect of interaction between extender types and semen packaging method:

Analysis of variance of all sperm characteristics studied indicated insignificant effect of interaction

Table 4 .Effect of interaction between extender types and semen packaging method on sperm characteristics in post-thawed Finnish ram semen.

\begin{tabular}{|c|c|c|c|c|c|}
\hline \multirow{2}{*}{$\begin{array}{l}\text { Type of } \\
\text { Extender }\end{array}$} & \multirow{2}{*}{$\begin{array}{c}\text { Packaging } \\
\text { Method }\end{array}$} & \multicolumn{4}{|c|}{ Sperm characteristics (\%) } \\
\hline & & Motility & Livability & Abnormality & Curled tail \\
\hline \multirow{2}{*}{ Tris-EY } & Straw & $45.71 \pm 2.02$ & $49.00 \pm 2.10$ & $34.30 \pm 1.63$ & $48.57 \pm 1.68$ \\
\hline & Pellet & $45.00 \pm 1.89$ & $43.57 \pm 1.25$ & $34.60 \pm 1.60$ & $44.71 \pm 3.04$ \\
\hline \multirow{2}{*}{ Tris-SBL } & Straw & $45.71 \pm 2.02$ & $48.85 \pm 2.20$ & $35.40 \pm 1.82$ & $48.71 \pm 1.55$ \\
\hline & Pellet & $44.28 \pm 1.70$ & $42.42 \pm 0.99$ & $35.60 \pm 1.39$ & $44.85 \pm 2.17$ \\
\hline \multirow{2}{*}{ Tris-BHT } & Straw & $45.00 \pm 1.89$ & $48.28 \pm 1.63$ & $37.60 \pm 1.85$ & $48.42 \pm 1.65$ \\
\hline & Pellet & $42.14 \pm 1.01$ & $41.57 \pm 1.19$ & $35.30 \pm 1.27$ & $44.71 \pm 1.99$ \\
\hline & & 0.83 & 0.91 & 0.67 & 0.99 \\
\hline
\end{tabular}

Antioxidant capacity and enzyme activity in postthawed seminal plasma:

Effect of extender type:

Antioxidant system, in terms of total antioxidants capacity (TAC) and malondialdehyde (MDA), were affected significantly $(\mathrm{P}<0.05)$ by type of extender. Results showed that TAC was significantly $(\mathrm{P}<0.05)$ higher, while MDA concentration was significantly $(\mathrm{P}<0.05)$ lower in Tris-SBL and Tris-BHT than in Tris-

Table 5. Total antioxidants capacity, malondialdehyde concentration and lactic dehydrogenase activity in seminal plasma of post-thawed Finnish ram semen as affected by the extender type.

\begin{tabular}{lccc}
\hline Extender Type & $\begin{array}{c}\text { Total antioxidants capacity } \\
(\mathbf{M m} / \mathbf{l})\end{array}$ & $\begin{array}{c}\text { Malondialdhyde } \\
(\mathbf{n m o l} / \mathbf{m l})\end{array}$ & $\begin{array}{c}\text { Lactic dehydrogenase } \\
(\mathbf{U} / \mathbf{m l})\end{array}$ \\
\hline Tris-EY & $1.87 \pm 0.14^{\mathrm{b}}$ & $1.53 \pm 0.18^{\mathrm{a}}$ & $357.97 \pm 61.55$ \\
Tris-SBL & $2.18 \pm 0.11^{\mathrm{ab}}$ & $0.92 \pm 0.04^{\mathrm{b}}$ & $304.91 \pm 44.07$ \\
Tris-BHT & $2.40 \pm 0.15^{\mathrm{a}}$ & $0.56 \pm 0.02^{\mathrm{b}}$ & $446.57 \pm 29.27$ \\
P-value & $0.03^{*}$ & $0.0005^{* * *}$ & 0.13 \\
\hline
\end{tabular}

* Significant differences at $\mathbf{P}<0.05$. *** Significant differences at $\mathbf{P}<0.001$.

Effect of semen packaging method:

Antioxidant system, in terms of TAC, MDA concentration and LDH activity in post-thawed Finnish

ram semen were not affected with semen packaging method, indicating similar sperm characteristics of ram semen frozen in straws or in pelleted form (Table 6).

Table 6. Total antioxidants capacity, malondialdehyde and lactic dehydrogenase activity in seminal plasma of post-thawed Finnish ram semen as affected by semen packaging method.

\begin{tabular}{lccc}
\hline Semen packaging method & $\begin{array}{c}\text { Total antioxidants capacity } \\
(\mathbf{M m} / \mathbf{l})\end{array}$ & $\begin{array}{c}\text { Malondialdhyde } \\
\text { (nmol/ml) }\end{array}$ & $\begin{array}{c}\text { Lactic dehydrogenase } \\
(\mathbf{U} / \mathbf{m l})\end{array}$ \\
\hline Straw & $2.02 \pm 0.09$ & $1.00 \pm 0.18$ & $415.84 \pm 48.64$ \\
Pellet & $2.27 \pm 0.15$ & $1.01 \pm 0.15$ & $323.80 \pm 26.52$ \\
P-value & 0.10 & 0.97 & 0.11 \\
\hline
\end{tabular}

Effect of the interaction between extender type and concentration and LDH activity were not significant, semen packaging method:

Effects of interaction between type of extender and semen packaging method on each of TAC, MDA reflecting better antioxidant defence system in semen packing in straws than in pellets form with all types of extenders (Table 7).

Table 7. Effect of the interaction between extender type and semen packaging method on total antioxidants capacity, malondialdehyde and lactic Dehydrogenase activity in seminal plasma of post-thawed Finnish ram semen.

\begin{tabular}{lcccc}
\hline Extender Type & $\begin{array}{c}\text { Packaging } \\
\text { Method }\end{array}$ & $\begin{array}{c}\text { Total } \\
\text { Antioxidants Capacity } \\
(\mathbf{M m} / \mathbf{l})\end{array}$ & $\begin{array}{c}\text { Malondialdhyde } \\
\text { (nmol/ml) }\end{array}$ & $\begin{array}{c}\text { Lactic dehydrogenase } \\
(\mathbf{U} / \mathbf{m l})\end{array}$ \\
\hline \multirow{2}{*}{ Tris-EY } & Straw & $1.76 \pm 0.12$ & $1.50 \pm 0.39$ & $418.24 \pm 121.64$ \\
& Pellet & $1.97 \pm 0.27$ & $1.56 \pm 0.14$ & $297.71 \pm 22.70$ \\
Tris-SBL & Straw & $2.18 \pm 0.14$ & $0.97 \pm 0.07$ & $338.19 \pm 80.05$ \\
& Pellet & $2.17 \pm 0.21$ & $0.87 \pm 0.06$ & $271.63 \pm 46.85$ \\
Tris-BHT & Straw & $2.12 \pm 0.10$ & $0.54 \pm 0.04$ & $491.09 \pm 36.50$ \\
& Pellet & $2.67 \pm 0.16$ & $0.59 \pm 0.03$ & 0.87 \\
\end{tabular}

\section{DISCUSSION}

The current study aimed to compare the effectiveness of soybean lecithin (SBL) or butylated hydroxytoluene (BHT) as an alternative component in the Tris-based extender, on sperm characteristics, including progressive motility, livability, abnormality and curled tail spermatozoa in post-diluted, postequilibrated and post-thawed semen. It is of interest to 
note that each of sperm motility and livability percentage in the present study had a positive relationship with the percentage of curled tail spermatozoa as affected by the type of extender or semen packaging methods. In the same way, Gil et al. (2003) and Salmani et al. (2014) reported that functional membrane integrity of spermatozoa has a positive effect and direct relationship with sperm motility. During cryopreservation, equilibration period was important for protecting sperm motility and membrane integrity (Leite et al., 2010). It is worth noting that each of Tris-SBL or Tris-BHT showed a lower rate of reduction in motility, livability and response to HOS-t and a lower rate of increase in abnormality of spermatozoa than Tris-EY after equilibration. Similar results were obtained by Khalifa and Abdel-Hafez (2014), who indicated that Tris-citric acid extender supplemented with $3.5 \mathrm{~g}$ soybean lecithin had higher progressive motility and viability than Triscitric acid extender supplemented with $15 \%$ egg yolk in post-equilibrated semen. This improvement may be attributed to that the observed reduction rate of sperm characteristics during refrigeration was attributed to changes in the $\mathrm{pH}$ of extension, osmolarity and growth of bacteria (Futino et al., 2010) in Tris-SBL or TrisBHT as compared to Tris-EY. Also, Shahverdi et al. (2014) observed significant interactions between equilibration time and extenders for sperm motility and membrane integrity. Freezing-thawing process negatively influenced sperm motility and livability, abnormality and membrane integrity. After freezing/thawing, ram semen had a nearly similar rate of change in all types of extenders. Similarly, El-Badry et al. (2014) found that addition of $15 \%$ egg yolk to an extender resulted in the highest sperm post-thaw motility, viability index, sperm membranes, acrosomal and DNA integrities. Depending on egg yolk which contains cholesterol, phospholipids, and low-density lipoprotein, it prevents the formation of ice crystal, thus protects sperm plasma membrane integrity against cold shock (Hu et al., 2010).

The present results indicated nearly similar effects of different types of extenders (Tris-EY, TrisSBL or Tris-BHT) on all sperm characteristics studied in frozen semen of Finnish rams. These findings are in agreement with previous studies on ram and goat semen cryopreservation which reported no differences between egg yolk and lecithin based extenders in viability, motility (Salmani et al., 2014) and functional membrane integrity of spermatozoa (Emamverdi et al., 2013). Similar results were reported on cryopreservation of ram (Forouzanfar et al. (2010) and goat (Roof et al. 2012) semen. Recently, Üstüner et al. (2014) indicated insignificant differences in the percentage of progressive motility in frozen-thawed ram semen diluted by extenders containing $1 \%$ soybean lecithin or $20 \%$ egg yolk. Also, Emamverdi et al. (2013) found insignificant differences in percentages of total motility and total abnormality in post-thawed semen diluted with Tris-SBL or Tris-EY extender. However, the addition of BHT in canine semen led to a significant improvement in semen quality (Neagu et al., 2010). This similarity may be due to that most semen extenders contain egg yolk and skim milk as sources of lipoprotein (Moussa et al., 2002), soybean contains high contents of lowdensity lipoproteins and egg yolk contains lecithin (Forouzanfar et al., 2010) that protects sperm cells against cold shock and other damage. SBL may play a more protective role for spermatozoa than egg yolk during the freezing-thawing process, and therefore reduces the risk of bacterial and mycoplasma into freezing extenders (Fukui et al., 2008). However, Zhang et al., (2009) reported that the boar sperm motion characteristics, plasma membrane integrity and acrosome integrity were superior in SBL-extender comparing with egg yolk extender. This is because of the provided poor protection by egg yolk for boar spermatozoa during cryopreservation unlike for bovine sperm (Benson et al., 1967; Bathgate et al., 2006).

Although both Tris-SBL and Tris-BHT extenders had similarity with Tris-EY, they reflected significant improvement in the antioxidant system of semen, in terms of increasing total antioxidant capacity and decreasing MDA concentration as well as increasing LDH activity in seminal plasma of post-thawed semen. This means a high level of lipid peroxidation (LPO) its end products (MDA) in Tris-EY extender than in the other extenders. Similar results were reported by Chelucci et al. (2015). Overall, egg yolk contains high levels of unsaturated fatty acids susceptible to LPO. Regardless of the source (polyunsaturated fatty acids from sperm cell membranes, from extenders or both), LPO which induced by ROS disrupts sperm motility and impairs all the sperm functions which are dependent on the integrity of plasma membrane, including spermoocyte fusion and ability to undergo acrosomal exocytose (Bansal et al., 2011). SBL as a substitute to egg yolk in semen extender may have played a protective role during freezing because of low viscosity, improvement of the sperm membrane function and rearrangements phospholipids of the sperm cells membrane (Fukui et al., 2008). Furthermore, the effective antioxidant components in soy lecithin as glutathione may protect the sperm viability through scavenging the LPO and prevention of MDA formation during freezing process (Salmani et al., 2014). Also, SBL extender recovered motility, plasma membrane and acrosome integrity, maintain semen quality, improve the freezability, apoptosis status and mitochondrial activity after thawing ram spermatozoa (Emamverdi et al., 2013; Singh et al., 2013). Molecular features revealed that sperm functionality in egg yolk extender was affected, as evidenced by lower DNA integrity, and higher lipid peroxidation in comparison with spermatozoa cryopreserved in soybean lecithin extender (Chelucci et al., 2015). As showed in this study, TrisBHT extender caused higher activity of LDH than in Tris-EY and Tris-SBL, respectively. The increase in activity of LDH enzyme was in accordance with the findings of Jones (1997), who reported that reduced LDH activity in seminal plasma indicated disturbed sperm function and metabolism. These findings may indicate higher microbial contamination of semen diluted with Tris-EY than that with Tris-SBL or Tris$\mathrm{BHT}$, being the best for the later extender.

Concerning the effect of semen packaging method, the present results indicated the superiority of straws as a better method for semen packaging as compared to pelleted form, regardless type of extender, in all sperm characteristics studied in ram semen after dilution, equilibration and thawing. Kowalczyk and Lukaszewicz (2015) found a 
higher reduction in sperm motility of frozen semen in pellets than in straws. The obtained better post-thawed motility and plasma membrane integrity of ram spermatozoa in straws than in pelleted form proved in our study were also reported in goats (Bezerra et al., 2012), boar (Dai et al., 2009). Also, Hunton et al. (1987) indicated that semen frozen in straws was more motile than pelleted semen, but both applied cryopreservation methods (pellets and straws) caused a decrease in the percentage of sperm livability. Pickett and Berndtson (1974) reported that superior sperm viability, greater storage efficiency, and higher conception rates resulting from storage in plastic straws have led to rapid increases in the use of this packaging technique. During cryopreservation, the plasma membrane integrity disruption caused by disarrangement of lipids within the membrane may encourage further cellular damage and then lead to sperm death (Chelucci et al., 2015). In addition, straws have been packaged with more hygienic semen, also the use of vials or straws readily allows the accurate identification of samples. Although pellets have the advantage of allowing a rapid drop in temperature to be achieved, they are not suited for easy identification after freezing. In addition, the re-use of the carbon dioxide block or metal plate carries the potential risk of cross-contamination with spermatozoa from the previous freezing. On the other hand, the use of straws considerably reduces the risk of cross-contamination during cryopreservation (Bezerra et al., 2012). In general, the present results did not reflect the significant effect of semen packaging method on total antioxidant capacity, MDA concentration or LDH activity.

The successful usage of Tris-SBL or Tris-BHT comparing with the possible disadvantages of using egg yolk, including its potential to be a cause of allergic reactions, the risk of bacterial contamination and its variable effect on semen, which may allow the save using SBL or BHT as an alternative of egg yolk in Trisbased extender of ram semen.

\section{REFERENCES}

Andrabi, S. (2007). Fundamental principles of cryopreservation of Bos taurus and Bos indicus bull spermatozoa. Ind. J. Agric. Biol. 2: 367369.

Awad, M. (1989). Studies on freezing ram semen by two different methods. M. Sc. Thesis, Animal Production Department, Faculty of Agriculture, Ismailia, Egypt.

Ax, R., Dally, M., Didion, B., Lenz, R., Love, C., Varner, D. and Bellin, M. (2000). Semen evaluation. Reproduction in Farm Animals, $7^{\text {th }}$ Edition, 363-375.

Bais, R. and Philcox, M. (1994). IFCC methods for the measurement of catalytic concentration of enzymes. Part 8. IFCC method for lactate dehydrogenase (L-lactate: NAD. Journal of Analytical Methods in Chemistry, 16(5): 167182.

Bansal, A.K., Gupta, R. and Kumar, R. (2011). Fuzzy estimator for the sensorless PMBLDC motor drive under speed reversal. Paper presented at the Power Electronics (IICPE), 2010 India International Conference.
Bathgate, R., Maxwell, W. and Evans, G. (2006). Studies on the Effect of Supplementing Boar Semen Cryopreservation Media with Different Avian Egg Yolk Types on in Vitro Post-thaw Sperm Quality. Reproduction in Domestic Animals, 41(1): 68-73.

Benson, R., Pickett, B., Komarek, R. and Lucas, J. (1967). Effect of incubation and cold shock on motility of boar spermatozoa and their relationship to lipid content. Journal of Animal Science, 26(5): 1078-1081.

Bezerra, S.B.L., Véras, A.S.C., Silva, D.K.D.A., Ferreira, M.D.A., Pereira, K.P., Santos, G.R.D.A. and Almeida, O.C.D. (2012). Morphometry and carcass characteristics of goats submitted to grazing in the Caatinga. Revista Brasileira de Zootecnia, 41(1): 131-137.

Chelucci, S., Pasciu, V., Succu, S., Addis, D., Leoni, G. G., Manca, M. E. and Berlinguer, F. (2015). Soybean lecithin-based extender preserves spermatozoa membrane integrity and fertilizing potential during goat semen cryopreservation. Theriogenology, 83(6): 1064-1074.

Clulow, J., Mansfield, L., Morris, L., Evans, G. and Maxwell, W. (2008). A comparison between freezing methods for the cryopreservation of stallion spermatozoa. Animal Reproduction Science, 108(3): 298-308.

Cotter, P., Goolsby, H. and Prien, S. (2005). Preliminary evaluation of a unique freezing technology for bovine spermatozoa cryopreservation. Reproduction in Domestic Animals, 40(2): 9899.

Daader, A. and Zeidan, A. (2008). Motility and acrosomal integrity of frozen rabbit spermatozoa as affected by different extenders, cryoprotectants and packaging methods. Paper presented at the Anais do $9^{\text {th }}$ World Rabbit Congress, Verona-Italia.

Dai, J., Wu, C., Zhang, D., Yin, F., Zhang, T., Liu, D. and Wang, L. (2009). Some factors affecting freezing of boar semen in $5 \mathrm{ml}$ maxi-straws. Asian-Aust. J. Anim. Sci, 22: 507-515.

Demianowicz, W. and Strezek, J. (1996). The effect of lipoprotein fraction of egg yolk on some of the biological properties of boar spermatozoa during storage of the semen in a liquid state. Reprod. Dom. Anim. 31: 279-80.

Duncan, D. B. (1955). Multiple ranges and multiple F tests. Biometrics, 11(1): 1-42.

El-Badry, D., Anwer, A.M. and Rawash, Z. (2014). Effect of different concentrations of sodium dodecyl sulfate, egg yolk and glycerol on the freezability and DNA integrity of Arabian stallion spermatozoa. Assiut Vet. Med. J., 60: 2935 .

Emamverdi, M., Zhandi, M., Zare Shahneh, A., Sharafi, M. and Akbari-Sharif, A. (2013). Optimization of Ram Semen Cryopreservation Using a Chemically Defined Soybean Lecithin-Based Extender. Reproduction in Domestic Animals, 48(6): 899-904.

Ferdinand, N., Ngwa, T.D., Augustave, K., Dieudonné, B.P.H., Willington, B.O., D'Alex, T.C. and Joseph, T. (2014). Effect of egg yolk concentration in semen extender, $\mathrm{pH}$ adjustment of extender and semen cooling methods on bovine semen characteristics. Global Veterinaria, 12: 292-298. 
Forouzanfar, M., Sharafi, M., Hosseini, S., Ostadhosseini, S., Hajian, M., Hosseini, L. and Nasr-Esfahani, M. (2010). In vitro comparison of egg yolk-based and soybean lecithin-based extenders for cryopreservation of ram semen. Theriogenology, 73(4): 480-487.

Fukui, Y., Kohno, H., Togari, T., Hiwasa, M. and Okabe, K. (2008). Fertility after artificial insemination using a soybean-based semen extender in sheep. Journal of Reproduction and Development, 54(4): 286-289.

Futino, D., Mendes, M., Matos, W., Mondadori, R. and Lucci, C. (2010). Glycerol, Methyl-Formamide and Dimethyl-Formamide in Canine Semen Cryopreservation. Reproduction in Domestic Animals, 45(2): 214-220.

Gil, J., Lundeheim, N., Söderquist, L. and RodríguezMartínez, H. (2003). Influence of extender, temperature, and addition of glycerol on postthaw sperm parameters in ram semen. Theriogenology, 59(5): 1241-1255.

Graham, J.K. and Foote, R.H. (1987). Effect of several lipids fatty acyl chain length and degree of unsaturation on the motility of bull spermatozoa after cold shock and freezing. Cryobiology, 24: $42-52$.

Haidl, G. and Schill, W. B. (1994). Assessment of sperm chromatin condensation: an important test for prediction of IVF outcome. Archives of Andrology, 32(3): 263-266.

Hu, J.H., Li, Q.W., Zan, L.S., Jiang, Z.L., An, J.H., Wang, L.Q. and Jia, Y.H. (2010). The cryoprotective effect of low-density lipoproteins in extenders on bull spermatozoa following freezing-thawing. Animal Reproduction Science, 117(1): 11-17.

Hunton, J., Flecker, S.E. and Maxwell, W. (1987). Pregnancy rates following intra-uterine insemination with a pellet or straw-frozen ram semen. The Journal of Agricultural Science, 109(1): 189-191.

Jones, A. (1997). Metabolism of lactate by mature boar spermatozoa. Reproduction, Fertility and Development, 9(2): 227-232.

Khalifa, E. and Abdel-Hafez, M. (2014). Effect of soybean lecithin-based semen extender on freezability and fertility of Rahmani ram spermatozoa. Egyptian Journal of Sheep and Goat Sciences, 9(1): 59-66.

Koracevic, D., Koracevic, G., Djordjevic, V., Andrejevic, S. and Cosic, V. (2001). Colorimetric method for determination of total antioxidant capacity. J. Clin. Pathol., 54: 356361.

Kowalczyk, A. and Łukaszewicz, E. (2015). Simple and effective methods of freezing capercaillie (Tetrao urogallus L.) semen. PLoS ONE 10(1): e0116797.

Leite, T.G., do Vale Filho, V.R., de Arruda, R.P., de Andrade, A.F.C., Emerick, L.L., Zaffalon, F.G. and de Andrade, V.J. (2010). Effects of extender and equilibration time on post-thaw motility and membrane integrity of cryopreserved Gyr bull semen evaluated by CASA and flow cytometry. Animal Reproduction Science, 120(1): 31-38.

Merino, O., Aguagüiña, W., Esponda, P., Risopatrón, J., Isachenko, E., Isachenko, V. and Sánchez, R. (2015). Protective effects of butylated hydroxytoluene on sperm function in human spermatozoa cryopreserved by vitrification technique. Andrologia, 47(2): 186-193.
Moussa, M., Martinet, V., Trimeche, A., Tainturier, D. and Anton, M. (2002). Low-density lipoproteins extracted from hen egg yolk by an easy method: cryoprotective effect on frozen-thawed bull semen. Theriogenology, 57(6): 1695-1706.

Naijian, H. R., Kohram, H., Shahneh, A. Z., Sharafi, M. and Bucak, M. N. (2013). Effects of different concentrations of BHT on microscopic and oxidative parameters of Mahabadi goat semen following the freeze-thaw process. Cryobiology, 66(2): 151-155.

Nair, S. J., Brar, A., Ahuja, C., Sangha, S. and Chaudhary, K. (2006). A comparative study of lipid peroxidation, activities of antioxidant enzymes and viability of cattle and buffalo bull spermatozoa during storage at refrigeration temperature. Animal Reproduction Science, 96(1): 21-29.

Neagu, V., García, B.M., Sandoval, C.S., Rodríguez, A.M., Ferrusola, C.O., Fernández, L.G. and Peña, F. (2010). Freezing dog semen in presence of the antioxidant butylated hydroxytoluene improves post-thaw sperm membrane integrity. Theriogenology, 73(5): 645-650.

Nur, Z., Zik, B., Ustuner, B., Sagirkaya, H. and Ozguden, C. (2010). Effects of different cryoprotective agents on ram sperm morphology and DNA integrity. Theriogenology, 73(9): 1267-1275.

Ohkawa, H., Ohishi, N. and Yagi, K. (1979). Assay for lipid peroxides in animal tissues by the thiobarbituric acid reaction. Analytical Biochemistry, 95(2): 351-358.

Pace, M. and Graham, E. (1974). Components of egg yolk which protect bovine spermatozoa during freezing. Journal of Animal Science, 39(6): 1144-1149.

Papa, F.O., Felício, G.B., Melo-Oña, C.M., Alvarenga, M.A., De Vita, B., Trinque, C. and Dell'Aqua, J.A. (2011). Replacing egg yolk with soybean lecithin in the cryopreservation of stallion semen. Animal Reproduction Science, 129(1): 73-77.

Pickett, B. and Berndtson, W. (1974). Preservation of bovine spermatozoa by freezing at straws: A review. Journal of Dairy Science, 57(11): 12871301.

Purdy, P. (2006). A review of goat sperm cryopreservation. Small Ruminant Research, 63(3): 215-225.

Rehman, F., Qureshi, M. and Khan, R. (2014). Effect of soybean-based extenders on sperm parameters of a Holstein-Friesian bull during liquid storage at $4^{\circ} \mathrm{C}$. Pakistan J. Zool, 46(1): 185-189.

Roof, D., Bowley, S., Price, L. and Matsas, D. (2012). Comparison of two commercial extenders for cryopreservation of goat semen without sperm washing. Theriogenology, 77(2): 412-420.

Sahashi, Y., Otsuki, T., Higaki, S., Nagano, M., Yamashita, Y. and Hishinuma, M. (2011). Effect of butylated hydroxytoluene on dog sperm longevity in chilling storage and cryopreservation. Journal of Veterinary Medical Science, 73(7): 895-899.

Salamon, S. and Maxwell, W. (2000). Storage of ram semen. Animal Reproduction Science, 62(1): 77 111.

Salmani, H., Towhidi, A., Zhandi, M., Bahreini, M. and Sharafi, M. (2014). In vitro assessment of soybean lecithin and egg yolk based diluents for cryopreservation of goat semen. Cryobiology, 68(2): 276-280. 
SAS (2004). SAS/STAT User's Guide. Version 8, Statistical Analysis Systems Institute, Inc., Cary, NC., USA.

Shahverdi, A., Rastegarnia, A. and Topraggaleh, T. R. (2014). Effect of extender and equilibration time on post-thaw motility and chromatin structure of buffalo bull (Bubalus bubalis) spermatozoa. Cell Journal (Yakhteh), 16(3): 279

Shoae, A. and Zamiri, M. (2008). Effect of butylated hydroxytoluene on bull spermatozoa frozen in egg yolk-citrate extender. Animal Reproduction Science, 104(2): 414-418.

Singh, V., Singh, A., Kumar, R. and Atreja, S. (2013). Development of soya milk extender for semen cryopreservation of Karan Fries (crossbreed cattle). Cryo-Letters, 34(1): 52-61.

Üstüner, B., Selim, A., Zekariya, N., Sağirkaya H. and Soylu, K. (2014). Effect of egg yolk and soybean lecithin on tris-based extender in post-thaw ram semen quality and in vitro fertility. Kafkas Üniversitesi Veteriner Fakültesi Dergisi, 20(3): 393-398.

Vidal, A. H., Batista, A. M., da Silva, E. C. B., Gomes, W. A., Pelinca, M. A., Silva, S. V. and Guerra, M. M. P. (2013). Soybean lecithin-based extender as an alternative to goat sperm cryopreservation. Small Ruminant Research, 109(1): 47-51.
Watson, P. and Anderson, W. (1983). Influence of butylated hydroxytoluene (BHT) on the viability of ram spermatozoa undergoing cold shock. Journal of Reproduction and Fertility, 69(1): 229-235.

Watson, P. and Martin, I. (1975). The influence of some fractions of egg yolk on the survival of ram spermatozoa at $5^{\circ} \mathrm{C}$. Australian Journal of Biological Sciences, 28(2): 145-152.

Wrathall, A., Holyoak, G., Parsonson, I. and Simmons, H. (2008). Risks of transmitting ruminant spongiform encephalopathies (prion diseases) by semen and embryo transfer techniques. Theriogenology, 70(5): 725-745.

Zhang, S., Hu, J., Li, Q., Jiang, Z. and Zhang, X. (2009). The cryoprotective effects of soybean lecithin on boar spermatozoa quality. African Journal of Biotechnology, 8 (22): 6476-6480.

Ziaullah, M., Ijaz, A., Aleem, M., Mahmood, A., Rehman, H., Bhatti, S. and Sohail, M. (2012). Optimal inclusion level of butylated hydroxytoluene in semen extender improves the quality of post-thawed canine sperm. Czech J. Anim. Sci, 57(8): 377-381.

\section{تأثير استخدام بعض المكونات البليلة لصفار البيض فى مخفف الترس على خصائص الحيوانات المنوية فى السائل

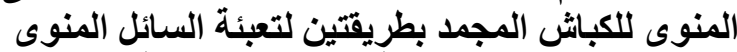

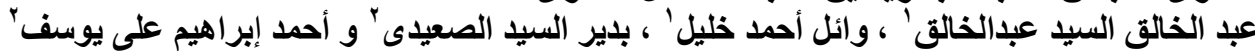

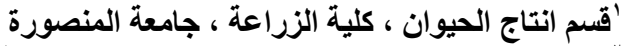 'معهد بحوث الاتتاج الحيوانى ، مركز البحوثة جامعة الزراعية، وزارة الزراعة}

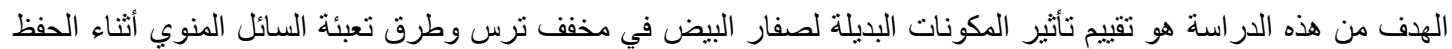

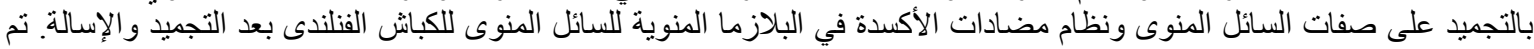

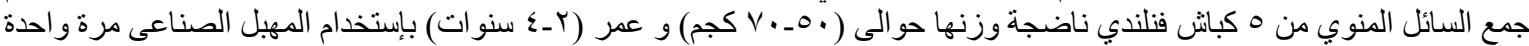

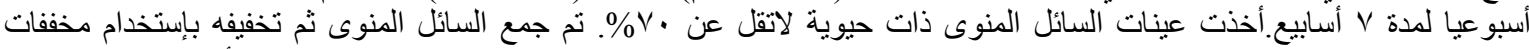

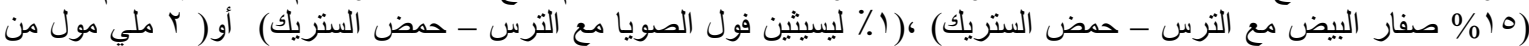

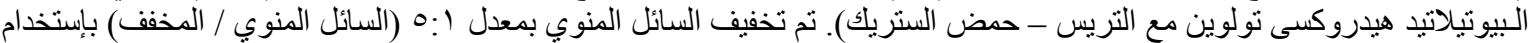

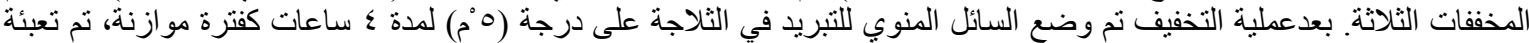

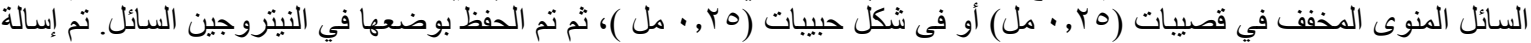

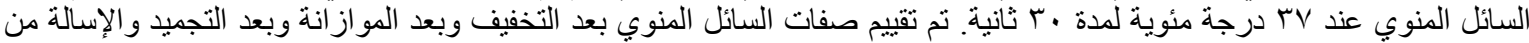

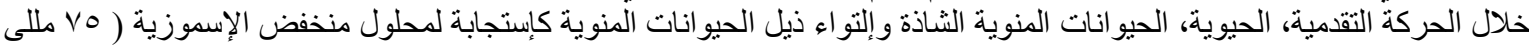

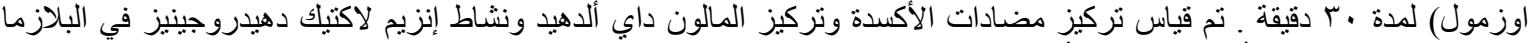

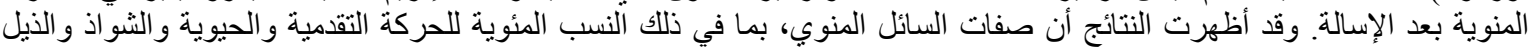

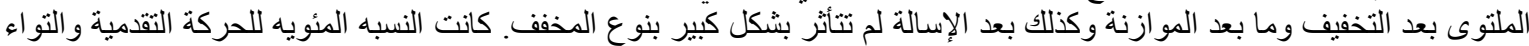

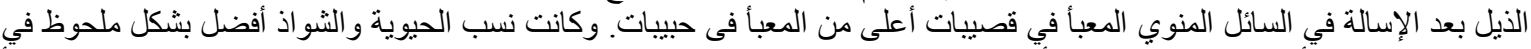

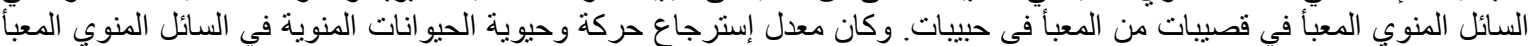

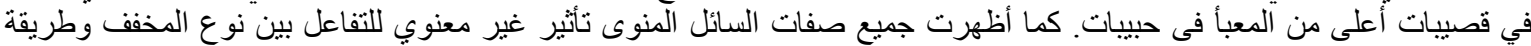

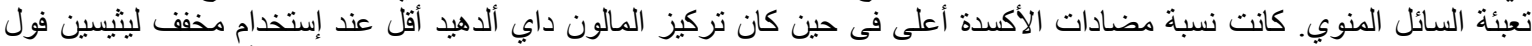

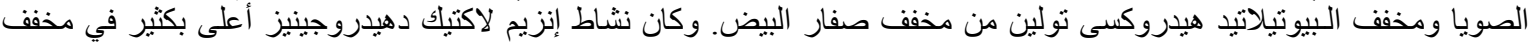

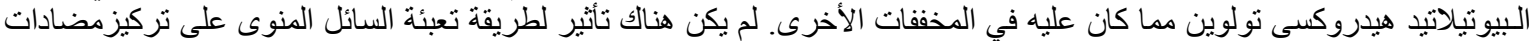

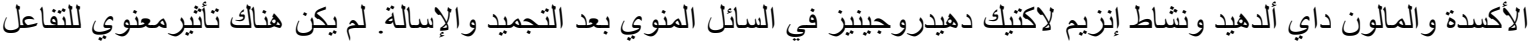

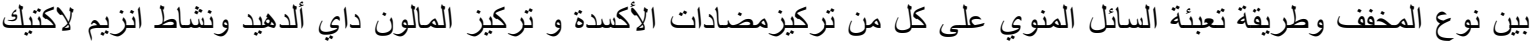

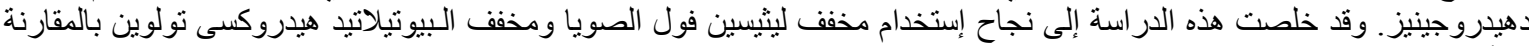
بالتأثير السلبى المحتمل عند إستخدام صفار البيض في مخفف الترس لتخفيف السائل المنوي للكباش. 